\title{
Fetal Cholelithiasis: Antenatal Diagnosis and Neonatal Follow-Up in a Case of Twin Pregnancy - A Case Report and Review of the Literature
}

(우(1) (8)

\author{
Authors \\ Yannick Hurni ${ }^{1}$, Francesco Vigo², Begoña Lipp von Wattenwyl², \\ Nicole Ochsenbein ${ }^{3}$, Claudia Canonica ${ }^{2}$ \\ Affiliations \\ 1 Obstetrics and Gynecology, Ospedale Regionale Bellinzona e \\ Valli, Bellinzona, Switzerland \\ 2 Obstetrics and Gynecology, Ospedale Regionale di Bellinzona e \\ Valli, Bellinzona, Switzerland \\ 3 Department of Obstetrics, University Hospital Zurich, Zürich, \\ Switzerland \\ Key words \\ fetal cholelithiasis, fetal gallstones, intrahepatic cholestasis of \\ pregnancy
}

received 31.03 .2016

revised 31.07.2016

accepted 05.12.2016

Bibliography

DOI http://dx.doi.org/10.1055/s-0042-123840

Ultrasound Int Open 2017; 3: E8-E12

(c) Georg Thieme Verlag KG Stuttgart · New York

ISSN 2199-7152

\author{
Correspondence \\ Yannick Hurni \\ Obstetrics and Gynecology \\ Ospedale Regionale Bellinzona e Valli \\ Ospedale Regionale Bellinzona e Valli, Bellinzona \\ 6500, Bellinzona \\ Switzerland \\ Tel.: + 41/763/342990 \\ yhurni@gmail.com
}

\section{ABSTRACT}

Fetal cholelithiasis is a rare finding during a third-trimester ultrasound with an average incidence rate of $0.07-1.15 \%$. We report a case of fetal cholelithiasis in twins, observed in a patient with monochorionic diamniotic twin pregnancy hospitalized at our unit for signs of premature labor. We present the outcome of the 2 neonates with a clinical and sonographic follow-up. In addition, we offer a comprehensive review of the literature available to date.

\section{Introduction}

The first descriptions of fetal cholelithiasis (FC) reported in the literature were the 2 cases diagnosed at the time of autopsy cited by Potter in 1928 [1], whereas the first prenatal diagnosis was reported in 1983 by Beretsky and Lankin [2]. FC is a rare and typically incidental finding during a third-trimester ultrasound exam. Although very few cases are reported in the literature, its frequency of diagnosis has increased over the last 20 years, probably due to technological progress and the increasing use of ultrasound examination during prenatal controls. In this article we report a case of FC in a monochorionic diamniotic twin pregnancy, associated with a cholestasis of pregnancy, afflicting the mother. In addition, we present a comprehensive review of the current literature available to date.

\section{Methods}

We prospectively collected and reviewed clinical and radiographic data of the above-mentioned patients. In addition, we performed a systematic review of the literature available to date. We used a multimethod approach to identify all reported cases of FC from 1980 to 2015. We performed a systematic search in the PubMed and Google Scholar databases. The terms used in the search were "fetal gallbladder" combined with any of the following words: "sludge", "gallstones", "lithiasis", and "echogenic material”. Other search terms were "fetal cholelithiasis", "fetal gallstones", and "prenatal/antenatal gallstones/cholelithiasis". We included all relevant original articles written in any language with an English abstract. Bibliographies of all included articles were reviewed for other relevant articles. We selected all of the articles reporting observed cases of FC. Articles describing FC but not reporting observed cases were rejected. We finally selected 28 articles with a total of 133 reported cases.

\section{Case report}

A 36-year-old woman (gravida 2, para 2), with a monochorionic diamniotic twin pregnancy, was hospitalized at 30 5/7 gestational weeks (GW) for premature contractions. The maternal medical situation highlighted a group B beta-hemolytic streptococcus positive test, an $\mathrm{AB}$ Rh + blood type, and a previous uncomplicated pregnancy with term vaginal delivery 4 years before. After the admission we established tocolytic therapy with hexoprenaline (from 30 5/7 GW), an antibiotic therapy with amoxicillin for 1 week and a 
- Table 1 Blood laboratory tests.

\begin{tabular}{|c|c|c|c|c|c|c|c|c|}
\hline & $\begin{array}{c}322 / 7 \\
\mathrm{GW}\end{array}$ & $\begin{array}{c}324 / 7 \\
\text { GW }\end{array}$ & $\begin{array}{c}326 / 7 \\
\mathrm{GW}\end{array}$ & $\begin{array}{c}333 / 7 \\
G W\end{array}$ & $\begin{array}{c}336 / 7 \\
G W\end{array}$ & $\begin{array}{c}344 / 7 \\
\text { GW }\end{array}$ & $\begin{array}{c}353 / 7 \\
\text { GW }\end{array}$ & $3^{\text {rd }}$ pp-day \\
\hline AST $(N<36)$ & 90 & 101 & 109 & 122 & 98 & - & 97 & 58 \\
\hline ALT $(N<37)$ & 163 & 192 & 201 & 272 & 232 & - & 190 & 94 \\
\hline GGT $(N<36)$ & 47 & 47 & 44 & - & - & - & 17 & - \\
\hline LDH $(N<500)$ & 283 & - & - & 353 & 322 & - & 379 & 495 \\
\hline Bile Acids $(\mathrm{N}<11.3)$ & 69 & - & - & - & 58 & 46 & - & 15 \\
\hline
\end{tabular}

$\mathrm{GW}=$ gestational weeks; $\mathrm{pp}=$ postpartum; AST = aspartate aminotransferase $(\mathrm{U} / \mathrm{L}) ; \mathrm{ALT}=$ alanine aminotransferase $(\mathrm{U} / \mathrm{L}) ; \mathrm{GGT}=\mathrm{gamma}-\mathrm{glutamyl}$ transferase $(\mathrm{U} / \mathrm{L})$; $\mathrm{LDH}=$ lactate dehydrogenase $(\mathrm{U} / \mathrm{L})$; bile acids $(\mu \mathrm{mol} / \mathrm{L})$
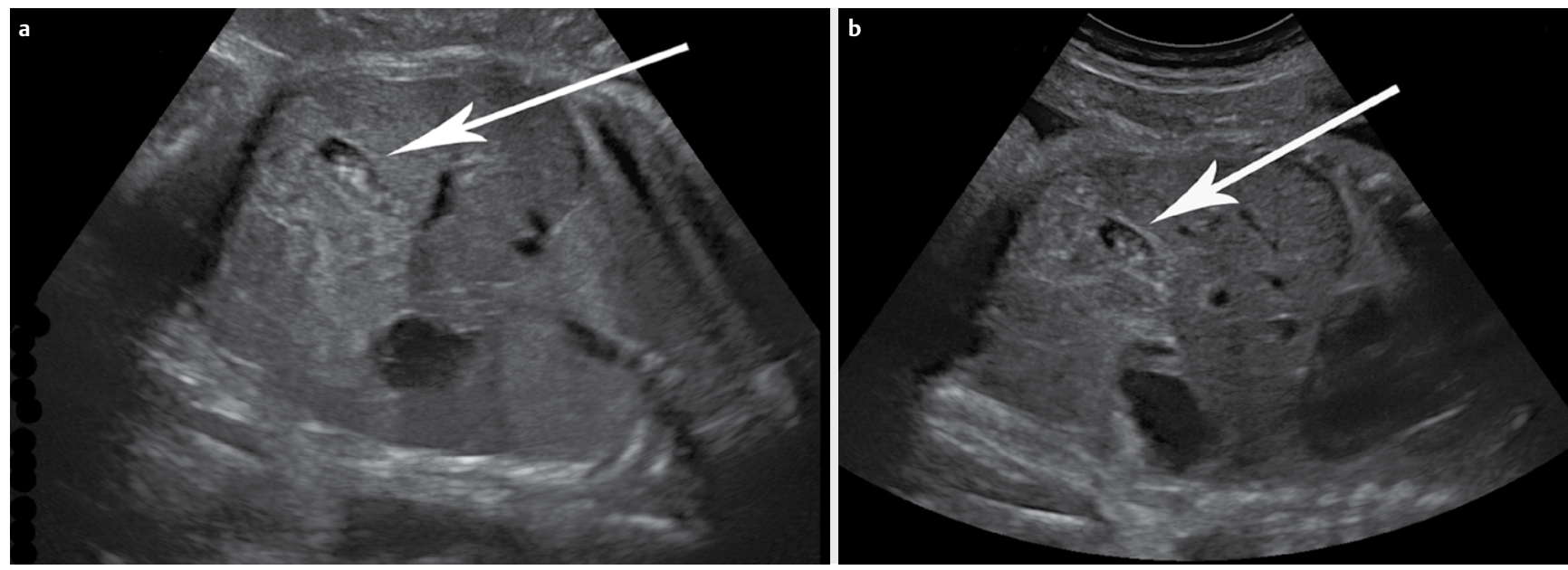

- Fig. 1 Ultrasound at 33 3/7 gestational weeks showing a hyperechogenic intra-cystic cholelithiasis in twin A and b suspected intra-cystic cholelithiasis in twin B. Abb. 1 Ultraschall bei 33 3/7 Schwangerschaftswochen zeigt a hyperechogene intrazystische Gallensteine bei Zwilling A und b. Verdacht auf intrazystische Cholelithiasis bei Zwilling B.

glucocorticoid therapy with betamethasone to induce fetal lung maturation. At 32 0/7 GW the patient reported a generalized cutaneous itch, especially on the palms of the hands and on the abdomen. The laboratory blood tests showed high levels of bile acids, and alteration of the common hepatic tests ( $\triangleright$ Table 1 ). Intrahepatic cholestasis of pregnancy was diagnosed. The patient was treated with a tritherapy with ursodeoxycholic acid, levocetirizine, and cholestyramine. At 33 3/7 GW, an ultrasound exam was performed. Twin A showed a cephalic position I, an estimated weight of $2400 \mathrm{~g}$ (83 $83^{\text {rd }}$ percentile), an amniotic fluid index in the normal range, and a hyperechogenic intra-cystic cholelithiasis ( $\mathbf{F i g} \mathbf{1 a}$ ). Twin B showed a cephalic position II, an estimated weight of $1900 \mathrm{~g}$ ( $30^{\text {th }}$ percentile), an amniotic fluid index in the normal range, and a suspected intra-cystic cholelithiasis ( $>$ Fig. 1b). At 36 0/7 GW an iterative cesarean section was performed, with no maternal complications during and after the surgery. During the postpartum period, we observed complete regression of the mother's itching symptoms and normalization of her laboratory tests ( $\triangleright$ Table $\mathbf{1}$ ). Because of an anemic state ( $\mathrm{Hb} 98 \mathrm{~g} / \mathrm{l}$ at second pp-day), the patient was treated with oral iron supplements. The 2 newborn males showed the following: twin A had a birth weight of $2915 \mathrm{~g}\left(50-75^{\text {th }}\right.$ percentile), a length of $50 \mathrm{~cm}$, a head circumference of $34 \mathrm{~cm}$, an Apgar score of 9/10/10, an umbilical artery $\mathrm{pH}$ of 7.26, and an umbilical vein $\mathrm{pH}$ of 7.31. Twin B showed a birth weight of $2230 \mathrm{~g}(25-$ $50^{\text {th }}$ percentile), a length of $47 \mathrm{~cm}$, a head circumference of
$32.5 \mathrm{~cm}$, an Apgar score of 9/9/10, an umbilical artery pH of 7.26, and an umbilical vein $\mathrm{pH}$ of 7.32. After birth, both neonates were transferred to the pediatric unit due to hypoglycemia. The measured glycemia was $2.2 \mathrm{mmol} / \mathrm{l}$ and $1.6 \mathrm{mmol} / \mathrm{l}$ for twin A and B, respectively. The newborns were treated with a glucose infusion from the first to the third postnatal day when the condition completely resolved. On the seventh postnatal day, a neonatal transabdominal ultrasound control was performed. We were able to confirm the diagnosis of cholecystolithiasis in twin B ( $\mathbf{F i g . ~ 2 a ) , ~ w h i l e ~ t h e ~ u l - ~}$ trasound of twin A showed no signs suggesting the presence of gallstones ( $\vee \mathbf{F i g} \mathbf{2} \mathbf{2 b}$ ), possibly due to complete intrauterine resolution. During the following months, twin B remained completely asymptomatic. An ultrasound at 6 months of life showed complete disappearance of the lithiasis. No further exams were undertaken. Currently, the children aged 2 years and 6 months are completely asymptomatic and have adequate food tolerance without associated disorders.

\section{Discussion}

Anomalies of the gallbladder, including biliary sludge and gallstones, are uncommon in fetal life. Their rate of incidence seems to be between $0.07 \%$ and $1.15 \%$ [3-8]. The etiopathogenesis of FC is currently unknown. In contrast to the cases of gallstones observed in pediatric and adult patients, where specific risk factors 

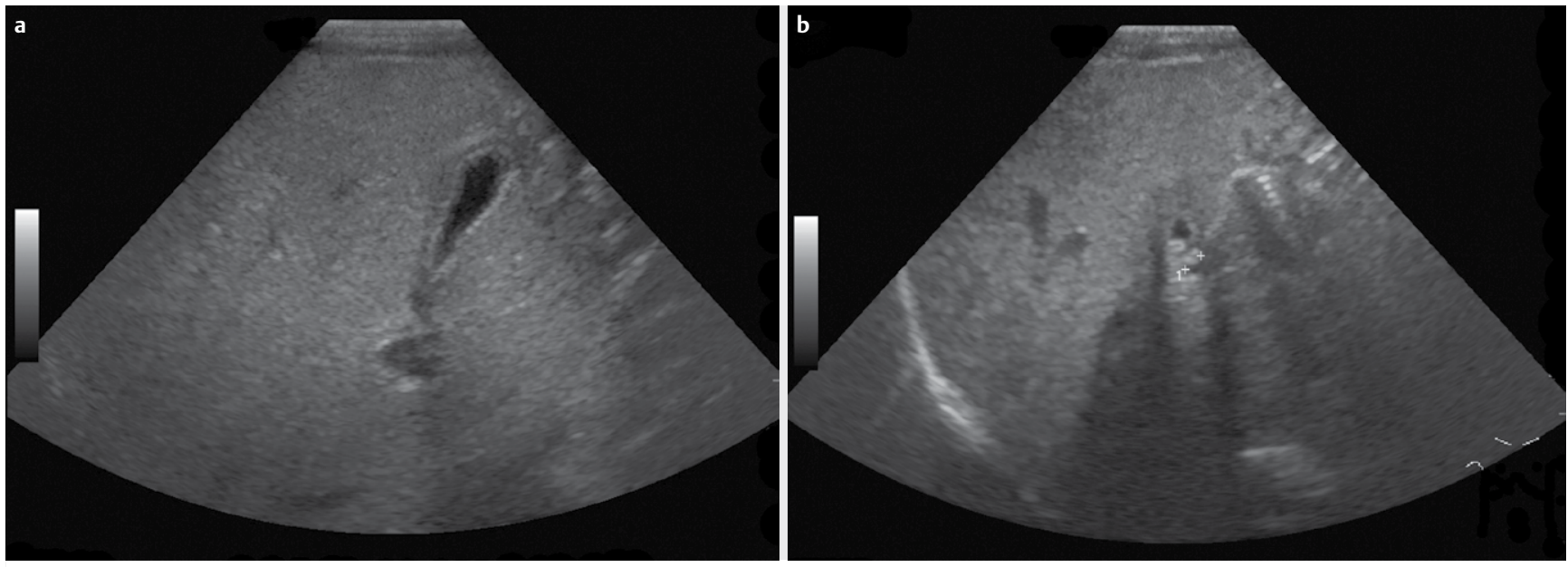

- Fig. 2 Transabdominal ultrasound on seventh postnatal day showing a no lithiasis in twin A's cholecyst and b hyperechogenic cholecystolithiasis in twin B. Abb. 2 Der transabdominale Neugeborenen-Ultraschall am 7. Lebenstag zeigt (a) keine Lithiasis in der Gallenblase von Zwilling A und (b) eine hyperechogene Chlezystolithiasis bei Zwilling B.

- Table 2 Maternal and fetal conditions associated with fetal cholelithiasis $[2-8,11-31]$.

\begin{tabular}{|c|c|}
\hline Maternal factors & $\begin{array}{l}\text { Number of } \\
\text { reported cases }\end{array}$ \\
\hline Hemolytic diseases & 1 \\
\hline Placental abruption & 2 \\
\hline History of cholelithiasis & 7 \\
\hline All types of diabetes & 6 \\
\hline Narcotics use (methadone) & 4 \\
\hline Ceftriaxone treatment & 1 \\
\hline Prostaglandin $\mathrm{E}_{2}$ treatment & 1 \\
\hline Twin pregnancy & 7 \\
\hline Twin pregnancy with fetal demise of one twin & 1 \\
\hline Intrahepatic cholestasis of pregnancy & 2 \\
\hline Increased estrogen and progestin levels & * \\
\hline Fetal factors & $\begin{array}{l}\text { Number of } \\
\text { reported cases }\end{array}$ \\
\hline Hemolytic diseases & 1 \\
\hline $\begin{array}{l}\text { Congenital malformations (cardiovascular, } \\
\text { gastrointestinal, urologic, skeletal) }\end{array}$ & 7 \\
\hline $\begin{array}{l}\text { Chromosome anomalies (trisomy 21, transloca- } \\
\text { tion } 10 ; 11 \text { ) }\end{array}$ & 2 \\
\hline Intrauterine growth restriction & 11 \\
\hline Oligohydramnios & 5 \\
\hline Polyhydramnios & 5 \\
\hline Prenatal leukemoid reaction & 1 \\
\hline Anomalies of the biliary tract & - \\
\hline Fetal-maternal blood group incompatibility & - \\
\hline
\end{tabular}

are well known, no established correlations are described for the fetal cases $[9,10]$. Several authors have suggested different maternal, obstetric, and fetal predisposing risk factors ( $>$ Table 2) [2$8,11-31]$. Some reported patients presented more than one risk factor, while others presented none. Although at least one associated factor was present in about 1 in 4 cases, the remaining three-quarters of patients presented no abnormality or special condition that could explain the FC. Even in cases associated with a proposed risk factor, it was often difficult to determine its actual contribution to the pathogenesis of this disorder.

Augmented erythrocyte degradation increases the bilirubin levels and has been shown to predispose to gallstone formation in postnatal life. An analogous situation could be involved in the development of FC during maternal or fetal hemolytic diseases, fetal-maternal blood group incompatibility, and following placental abruption or single-fetal demise in twin pregnancy $[2,4,5$, $11,14,25,29,30]$. Ceftriaxone is known to enhance the precipitation of insoluble calcium salts, which is a predisposing factor for cholelithiasis [32]. During pregnancy, the transplacental passage of ceftriaxone could produce the same effect on the fetal gallbladder, inducing gallstone formation [31]. Conditions associated with raised maternal estrogen and progestin levels (e. g., twin pregnancy) could predispose the patient to FC as a result of increased cholesterol secretion and the reduction of biliary acids synthesis $[11,14,25]$. Maternal narcotic use could reduce gastrointestinal activity, increasing gallbladder emptying time and resulting in augmented lithogenicity [3]. A maternal history of gallstones has been observed in 7 cases, suggesting a possible genetic predisposition to cholelithiasis $[11,14,18]$. In addition, maternal diabetes [14, 24], prostaglandin use [4], prenatal fetal leukomoid reaction [4], chromosomal aberrations [4], intrauterine growth restriction [3, 4, 13$15,17,27]$, amniotic fluid disorders [4, 7, 13, 14, 17, 24, 25, 31], and different cardiac, gastrointestinal, and urologic malformations $[4,7,13,14]$ have been observed in association with FC, but no clear correlation has been proposed. Some authors have suggested that FC may be sex-linked [7, 11, 18, 26, 31]. After having analyzed the totality of the reported cases, no significant difference between the 2 sexes has been observed (62 males and 56 females) [2$5,7,8,11-19,21,23-27,29-31]$. In our case, we hypothesize that the cholestatic effects of the raised circulating reproductive hor- 
mones associated with twin pregnancy, combined with a genetic predisposition of the 3 subjects, could have played an important role in the pathogenesis behind both the maternal intrahepatic cholestasis of pregnancy and the FC [14, 33, 34]. However, a direct effect of the elevated maternal bile acids on the fetal lithogenicity could not be excluded.

The FC appears to be a specific condition of the third trimester of pregnancy. All but 3 cases reported in the literature were diagnosed after 28 weeks of gestation [15, 27, 31]. Even in the systematic control of 1656 consequent high-risk pregnancies examined before 28 weeks of gestation by Kiserud et al., no case of FC was discovered [4]. Starting with the second trimester, it is possible to visualize the fetal gallbladder on ultrasonography. It appears as an elliptical, anechogenic structure placed on the right side of the intrahepatic umbilical vein $[35,36]$. Echogenic material in the fetal gallbladder can be observed in the form of single, multiple, or diffuse foci. The diffuse form, known as "biliary sludge", seems to be a precursor of gallstones, and was reported to be present in around $40 \%$ of cases [3-7, 11, 12, 14, 20, 25]. Unlike in pediatric and adult patients, FC may present with extremely varied ultrasound features. Echogenicity, homogeneity, and degrees of acoustic shadowing may vary greatly from one case to another. This wide range of possibilities may make the diagnosis difficult. It is extremely important to ascertain the intra-cholecystic position of echogenic foci in order to distinguish between gallstones and other possible sources of echogenicity in the right upper quadrant [30]. If FC is substantially a benign state, other conditions, such as hepatic calcifications, calcified hepatic masses, or meconial peritonitis, may be related to a high degree of morbidity and mortality $[17,18,30]$. In special situations, such as when the gallbladder is contracted, differentiation between them may prove very difficult $[11,27]$.

It is a common belief that FC resolves spontaneously with hydration and feeding soon after birth. Stringer et al. have proposed that characteristic conditions of the postnatal period, such as increased bile flow and changes in its composition, may allow for the dissolution of gallstones and their subsequent passage through the bile ducts [27]. In the literature, there have been 63 reported cases of FC with postnatal ultrasonographic follow-up to complete resolution $[2-8,11-19,21,23,24,26-31]$. More than $70 \%$ of the patients had resolution within 2 months from birth, and more than $90 \%$ within 6 months. Persistence beyond 12 months has been observed in only 2 patients [3, 31]. No substantial difference in resolution time has been observed between patients presenting solid gallstones and biliary sludge. The majority of the patients were treated conservatively, which, in most cases, meant by observation alone. 5 were treated with ursodeoxycholic acid with the intent to allow rapid resolution and decrease the risk of complications, but no relevant differences have been observed among the other cases $[8,11,23]$. Until now, only 3 cases of suspected FC requiring surgery have been reported $[15,21,37]$.

In contrast to pediatric and adult cases of gallstones, where spontaneous resolution is rare and surgery is often required, FC seems self-limiting. A conservative attitude appears to be suitable. Ultrasound exams are recommended at birth and until complete resolution. No medical treatment is advised, and surgery should be reserved for those rare symptomatic cases accompanied by complications. It has been suggested that FC may predispose individuals to future gallstone formation [2], but up to now no specific cases have been reported.

\section{Conclusion}

With this case, we report the association between FC and intrahepatic cholestasis of pregnancy, which was previously hypothesized by some authors, but had never been previously confirmed. Several questions remain unanswered about the actual frequency, pathogenesis and etiology of fetal cholelithiasis. What we do know is its self-limiting and benign character. Considering its high rate of spontaneous resolution, we recommend reassuring parents and closely observing the clinical evolution of the patients, without any medical or surgical treatment. However, clinical and ultrasonographic follow-up should continue until demonstration of resolution.

\section{Conflict of Interest}

No conflict of interest has been declared by the author(s).

\section{References}

[1] Potter AH. Gall-bladder disease in young subjects. Surg Gynecol Obstet 1928; 46: 795-808

[2] Beretsky I, Lankin DH. Diagnosis of fetal cholelithiasis using real-time high-resolution imaging employing digital detection. J Ultrasound Med 1983; $2: 381-383$

[3] Devonald KJ, Ellwood DA, Colditz PB. The variable appearances of fetal gallstones. J Ultrasound Med 1992; 11: 579-585

[4] Kiserud T, Gjelland K, Bognø H, Waardal M, Reigstad H, Rosendahl K. Echogenic material in the fetal gallbladder and fetal disease. Ultrasound Obstet Gynecol 1997; 10: 103-106

[5] Agnifili A, Verzaro R, Carducci G, Mancini E, Gola P, Marino M et al. Fetal cholelithiasis: a prospective study of incidence, predisposing factors, and ultrasonographic and clinical features. Clin Pediatr (Phila) 1999; 38: 371-373

[6] Müller R, Döhmann S, Kordts U. Fetale Gallenblase und Gallensteine. Ultraschall Med 2000; 21: 142-144

[7] Cancho Candela R, Díaz González J, Perandones Fernández C, Viñuela Rueda B, Relea Sarabia A, Andrés de Llano JM. Material ecogénico en vesícula biliar fetal: diagnóstico prenatal y seguimiento posnatal. An Pediatr (Barc) 2004; 61: 326-329

[8] Munjuluri N, Elgharaby N, Acolet D, Kadir RA. Fetal gallstones. Fetal Diagn Ther 2005; 20: 241-243

[9] Svensson J, Makin E. Gallstone disease in children. Semin Pediatr Surg 2012; 21: 255-265

[10] Afdhal NH. Epidemiology, risk factors, and pathogenesis of gallstones. In: Afdhal NH (ed.). Gallbladder and Biliary Tract Diseases. New York: Marcel Dekker, Inc.; 2000: 127-146

[11] Iroh Tam P-Y, Angelides A. Perinatal detection of gallstones in siblings. Am J Perinatol 2010; 27: 771-774

[12] Abbitt PL, Mcllhenny J. Prenatal detection of gallstones. J Clin Ultrasound 1990; 18: 202-204

[13] Broussin B, Daube E. La lithiase vésiculaire foetale. A propos de trois observations et revue de la littérature. J Gynecol Obstet Biol Reprod (Paris) 1990; 19: 90-95 
[14] Brown DL, Teele RL, Doubilet PM, DiSalvo DN, Benson CB, Van Alstyne GA. Echogenic material in the fetal gallbladder: sonographic and clinical observations. Radiology 1992; 182: 73-76

[15] Clarke JP, Roman JD. The outcome of two cases of fetal cholelithiasis. N Z Med J 1994; 107: 270

[16] Heijne L, Ednay D. The development of fetal gallstones demonstrated by ultrasound. Radiography 1985; 51: 155-156

[17] Hertzberg BS, Kliewer MA. Fetal gallstones in a contracted gallbladder: potential to simulate hepatic or peritoneal calcification. J Ultrasound Med 1998; 17: 667-670

[18] Holloway S, Edwards H. Antenatal diagnosis of fetal cholelithiasis. Ultrasound 2010; 18: 152-154

[19] Klingensmith WC, Cioffi-Ragan DT. Fetal gallstones. Radiology 1988; 167: $143-144$

[20] Lariviere M. Having K, Bullock S. Fetal Cholelithiasis. Journal of Diagnostic Medical Sonography 2006; 22: 403-406

[21] López Gutiérrez JC, Ros Mar Z, López Santamaría M, Díez Pardo JA, González Gonzalez A, Pastor Abascal I et al. Colelitiasis fetal. Caso clínico y revisión de la literatura. An Esp Pediatr 1990; 32: 468-469

[22] Nishi T. Ultrasonographic diagnosis of fetal cholelithiasis. J Obstet Gynaecol Res 1997; 23: 251-254

[23] Ozgun MT, Batukan C, Ozcelik B, Serin S, Basbug M. Prenatal sonographic diagnosis of fetal gallstones: a case report. Ultrasound Obstet Gynecol 2006; 28: 535-536

[24] Petrikovsky B, Klein V, Holsten N. Sludge in fetal gallbladder: natural history and neonatal outcome. Br J Radiol 1996; 69: 1017-1018

[25] Sepulveda W, Stagiannis KD. Echogenic material in the fetal gallbladder in a surviving monochorionic twin. Pediatr Radiol 1996; 26 : 129-130

[26] Sheiner E, Abramowicz JS, Hershkovitz R. Fetal gallstones detected by routine third trimester ultrasound. Int J Gynaecol Obstet 2006; 92: 255-256
[27] Stringer MD, Lim P, Cave M, Martinez D, Lilford R]. Fetal gallstones. ] Pediatr Surg 1996; 31: 1589-1591

[28] Suchet IB, Labatte MF, Dyck CS, Salgado LA. Fetal cholelithiasis: a case report and review of the literature. J Clin Ultrasound 1993; 21: 198-202

[29] Suma V, Marini A, Bucci N, Toffolutti T, Talenti E. Fetal gallstones: sonographic and clinical observations. Ultrasound Obstet Gynecol 1998; 12: $439-441$

[30] Triunfo S, Rosati P, Ferrara P, Gatto A, Scambia G. Fetal cholelithiasis: a diagnostic update and a literature review. Clin Med Insights Case Rep 2013; 6: 153-158

[31] Troyano-Luque J, Padilla-Pérez A, Martínez-Wallin I, Alvarez de la Rosa M, Mastrolia SA, Trujillo JL et al. Short and long term outcomes associated with fetal cholelithiasis: a report of two cases with antenatal diagnosis and postnatal follow-up. Case Rep Obstet Gynecol 2014; doi: $10.1155 / 2014 / 714271$

[32] Rodríguez Rangel DA, Pinilla Orejarena AP, Bustacara Diaz M, Henao García L, López Cadena A, Montoya Camargo R et al. Cálculos biliares asociados al uso de ceftriaxona en niños. Anales de Pediatría 2014; 80 : $77-80$

[33] Geenes V, Williamson C. Intrahepatic cholestasis of pregnancy. World ] Gastroenterol 2009; 15: 2049-2066

[34] Almashhrawi AA, Ahmed KT, Rahman RN, Hammoud GM, Ibdah JA. Liver diseases in pregnancy: diseases not unique to pregnancy. World J Gastroenterol 2013; 19: 7630-7638

[35] Moon MH, Cho JY, Kim JH, Lee YH, Jung SI, Lee MS et al. In Utero Development of the Fetal Gall Bladder in the Korean Population. Korean Journal of Radiology 2008; 9: 54-58

[36] Albay S, Malas MA, Koyuncu E, Evcil EH. Morphometry of the gallbladder during the fetal period. Surg Radiol Anat 2010; 32: 363-369

[37] Gertner M, Farmer DL. Laparoscopic cholecystecomy in a 16-day-old infant with chronic cholelithiasis. J Pediatr Surg 2004; 39: E17-E19 